\title{
Factors Influencing the Mode I Interlaminar Fracture Toughness of a Rubber Toughened Thermoplastic Matrix Composite
}

\author{
D. S. PARKER AND A. F. YEE \\ Materials Science and Engineering Department \\ University of Michigan \\ Ann Arbor, Michigan 48109
}

\begin{abstract}
The use of a rubber modified thermoplastic resin has been investigated as a method to improve the Mode I interlaminar fracture toughness of a unidirectional continuous carbon fiber composite. Test results show that the improvement in the fracture toughness is less than expected due to rubber particle agglomeration, solvent and molding induced crystallization of the matrix and poor fiber/matrix adhesion. The plastic zone in composites utilizing tough matrices can extend well beyond a single interfibrillar spacing. However, the development of the plastic zone is limited due to the failure of the fiber/ matrix interface. In order to fully evaluate the potential of tough composites using toughened matrices, any improvement made in the matrix toughness must be coupled with improvements in the fiber/matrix adhesion.
\end{abstract}

\section{INTRODUCTION}

$\mathbf{H}$ IGH PERFORMANCE CONTINUOUS fiber composites offer stiffness and strength which are superior to metals on a per weight basis [1]. This has led to an increase in the use of composites in the aerospace and automotive industries. Originally stiffness, strength and thermal stability were the primary criteria for choosing a fiber/matrix combination. The most commonly used polymeric matrices and fibers were epoxies, and glass and graphite fibers. Since the development of high strain to failure fibers, the emphasis has shifted to the production of a very tough composite with a high strain to failure.

A major problem with composites based on brittle matrices is that they have a low interlaminar fracture toughness and are sensitive to out of plane impact which results in a low compressive strength after impact $[2,3]$. The latter quantity can be reduced by as much as fifty percent [3]. The weakest fracture mode in composites is crack propagation between plies (delamination) or within plies parallel to the fibers (splitting) $[4,5]$. Crack propagation is influenced by three primary variables: fiber/matrix adhesion, matrix toughness and fiber volume 
fraction. In high performance composites, the fiber volume fraction is maximized. Assuming good fiber/matrix adhesion, crack propagation will be controlled by properties of the matrix $[3,6-8]$. Therefore, to improve the damage tolerance of a composite, research efforts have been focused on producing tough or damage tolerant high performance composites through modification of the matrix.

Simply introducing a toughened resin as a matrix material does not necessarily bring about a substantial improvement in a composite's fracture toughness. Hunston and co-workers have recently compiled some fracture data comparing a resin's fracture toughness to that of a composite utilizing the same resin as a matrix material $[9,10]$. Due to differences in the fiber volume fractions, testing rates and conditions, etc. it may be difficult to compare the test results, however, the trends are very interesting. For brittle epoxy resins with a strain energy release rate value $<200 \mathrm{~J} / \mathrm{m}^{2}$, the corresponding composite's interlaminar fracture toughness $\left(G_{I c}\right)$ value can be as high as three times that of the matrix resin's bulk value. However, for tough matrix resins such as rubber modified epoxies and thermoplastic resins, the composite's $G_{I c}$ value is about one third that of the matrix resin. Reasons cited for these lower than expected values are: 1) when utilizing tough resins as matrix materials the plastic zone size is constrained by the fibers $[8,9,14], 2$ ) for systems which have been rubber toughened the particles may be too large in diameter [12], 3) poor fiber matrix adhesion $[2,8,11,13]$ and 4) residual stresses due to processing [14].

In order to develop toughened composites utilizing tough matrix resins, we must provide answers to the following questions. What are the primary deformation mechanisms that are operative within the highly constrained interfibril regions of a composite? Are the toughening techniques used for neat resins useful for enhancing these deformation mechanisms? And finally, what variables are important to allow the toughening method chosen to operate within a composite laminate?

Our objective then is to determine these deformation mechanisms and develop an appropriate toughening technique which will bring about an increase in interlaminar fracture toughness.

Because thermoplastic matrix composites have the potential for producing very tough composites, we have investigated the use of a toughened thermoplastic resin as a matrix material for a continuous fiber composite. Our model composite consists of a polycarbonate (PC) matrix which has been toughened using submicron rubber particles. The particle toughening technique is described in the included references [15-18]. Though this work will involve a thermoplastic matrix material, it should not preclude transferring the insight gained here to other types of polymer matrix composites.

Through this work, we have discovered a number of processing factors which produce a weak fiber/matrix interface in a toughened thermoplastic matrix composite which in turn limits the composite's fracture toughness. These limiting factors are the focus of our discussion. Although some of these variables are specific to our approach to toughening a thermoplastic matrix composite, others are independent of the toughening technique. 


\section{MATERIALS}

Polycarbonate (General Electric Lexan ${ }^{\circledR} 141$ resin) was blended with 5 and 10 wt\% impact modifier using a twin screw extruder. The impact modifiers (IM) used were Acryloid ${ }^{\circledR}$ KM330 and KM653 (products of Rohm \& Haas). These are core/shell impact modifiers consisting of a glassy shell and a rubbery core. The advantage of using the Acryloid ${ }^{\circledR}$ impact modifiers is that the particle size and shape are not influenced by the processing condition and that they are submicron in diameter which allows them to fit within the interfibrillar space.

Composite prepregs were made using the modified and unmodified PC resins and Hercules AS4 (12K tow) continuous graphite fibers. The composites were produced by NASA-Langley using a solution prepregging method. The prepreg solution consisted of a 50:50 mixture of methylene chloride and chloroform containing $17 \mathrm{wt} \%$ solids. Twenty-four ply unidirectional $\left(\left[0^{\circ}\right]_{24}\right)$ composite plates $152.4 \times 152.4 \times 3.3 \mathrm{~mm}$ (approximately $65 \mathrm{wt} \%$ fibers) were produced by compression molding. A $.013 \mathrm{~mm}$ thick Kapton ${ }^{\otimes}$ film was folded and inserted into the midplane of the composite prior to compression molding to act as a starter crack.

\section{MECHANICAL TESTING}

The fracture toughness of the bulk resins was determined using a J-integral technique. The specific testing method and results are described in another paper [19].

The interlaminar fracture toughness $\left(G_{I_{c}}\right)$ was determined using a hinged double cantilever beam (HDCB) test. The sample dimensions are shown in Figure 1. The tests were conducted at $25^{\circ} \mathrm{C}$ using a displacement rate of 12.7 $\mathrm{mm} / \mathrm{min}$. The $G_{I c}$ values were determined using an area integration method described in Reference [20].

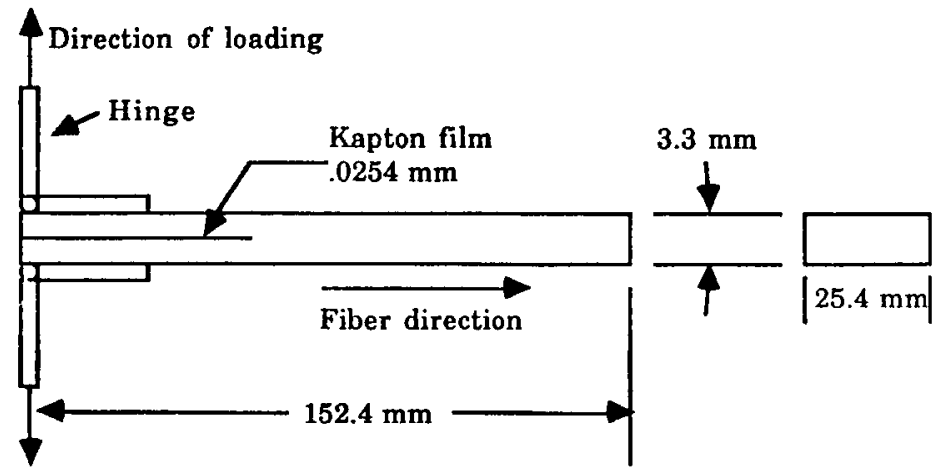

Figure 1. Schematic of the hinged double cantilever beam (HDCB) specimen (24 ply unidirectional). 


\section{MICROSCOPY}

Analysis of the fracture features of the composite materials was conducted using a Hitachi S-520 Scanning Electron Microscope (SEM). Subsurface analysis was performed by utilizing a petrographic thin sectioning technique in conjunction with an optical light microscope equipped with crossed polarizers. The thin sectioning technique allows the morphological structure within the composite and the deformation mechanisms to be analyzed and is described in Reference [21].

\section{RESULTS}

\section{Matrix Resin Fracture Toughness}

The results of the $\mathrm{J}$-Integral tests are shown in Table 1 . These results indicate that PC can be toughened by using the submicron core/shell impact modifiers. Further discussions regarding the $\mathbf{J}$-integral results will be presented in a forthcoming paper [19].

\section{Composite Fracture Toughness}

The first set of composites tested were made using the neat PC resin and the $10 \mathrm{wt} \%$ rubber modified resins. The results of the HDCB tests are shown in Table 2. The impact modified matrix materials produced a lower interlaminar fracture toughness value as compared to the neat PC matrix composite.

Analyzing the fracture surface using the SEM indicates that poor adhesion at the fiber/matrix interface is a common characteristic with all of these materials, as shown in Figure 2. In addition to the poor fiber/matrix interface, the rubber particles also appear to be detrimental to the interlaminar fracture toughness. In order to understand this effect, we had to locate where the rubber particles were within the composite. To this end, the fractured DCB specimens were etched using a saturated solution of sodium hydroxide and methanol. An SEM photomicrograph of the resultant surface is shown in Figure 3. This etchant preferentially removes the PC matrix, leaving the rubber particles exposed. The rubber particles were found to be agglomerated and to lie along the fiber/matrix interface. The rubber particle agglomeration is probably a result of the solvent used during the fiber impregnation process. By observing glass vials containing the prepregging mixture (50:50 mixture of methylene chloride and chloroform +17 wt \% solids) we found that separation occurred readily. The top portion of each vial consisted of a cloudy layer. A sample from both the top and the bottom of each vial was analyzed using dynamic light scattering. These results indicated that each layer had the same particle size distribution; however. the top layer contained approximately ten times more particles than the bottom layer. Therefore. we concluded that the rubber particles had risen to the top of the prepregging solution. During impregnation of the fibers the action of separation would cause the fibers to be preferentially coated with a high concentration of rubber par- 
Table 1. J-Integral fracture toughness results of polycarbonate toughened with Acryloid ${ }^{\mathrm{B}}$ impact modifiers.

\begin{tabular}{lc}
\hline Material & $\begin{array}{c}\boldsymbol{J}_{\mathbf{l c}} \\
\left(\mathbf{k J} / \mathbf{m}^{2}\right)\end{array}$ \\
\hline Polycarbonate & 2.50 \\
PC + 5 wt\% KM330 & 5.29 \\
PC + 10wt\% KM330 & 5.86 \\
PC + 5 wt \% KM653 & 5.23 \\
PC + 10wt\% KM653 & 5.68 \\
\hline
\end{tabular}

All tests were done at $25^{\circ} \mathrm{C}$ using a displacement rate of $2.54 \mathrm{~mm} / \mathrm{sec}$.

ticles. The impact modifiers would not be expected to bond very well to the fibers and therefore would reduce the adhesion at the fiber/matrix interface.

Thin sections of the tested composites were produced in order to observe the plastic zone in the materials and are shown in Figure 4. A plastic zone was not found; however, we did observe that the PC matrix contained crystalline regions. The crystallinity is the result of two factors: 1) by analyzing a sample of the prepregs using a differential scanning calorimeter (DSC), we determined that as the prepreg solvent evaporated, the PC matrix became crystallized. A DSC scan of a prepreg sample reveals that the $\mathrm{PC}$ matrix has a melting point at $242{ }^{\circ} \mathrm{C}$ (Figure $5)$; 2) the molding practice used to produce the composites involved raising the temperature to $265^{\circ} \mathrm{C}$ (the melting point of crystalline $\mathrm{PC}$ is in the range of $245-255^{\circ} \mathrm{C}$ ) for 20 minutes. The next step involved cooling to $245^{\circ} \mathrm{C}$ and holding at this temperature for 2 hours followed by cooling to room temperature. If all of the crystalline material is not eliminated while holding at $265^{\circ} \mathrm{C}$. then spherulitic growth may be easily initiated at the subsequent hold at $245^{\circ} \mathrm{C}$. Work performed by Kardos on a 20 vol. \% randomly oriented graphite fiber PC composite showed that the fibers themselves act as nucleation sites for spherulitic growth [22]. He suggested also that the presence of a crystalline layer along the

Table 2. HDCB test results-10 wt\% impact modified matrix.

\begin{tabular}{llcc}
\hline Sample I.D. & Matrix Resin & $\begin{array}{c}\text { Wt\% } \\
\text { Resin }\end{array}$ & $\begin{array}{c}\mathbf{G}_{\mathbf{l c}} \\
\left(\mathbf{k J} / \mathbf{m}^{2}\right)\end{array}$ \\
\hline HDCB-PC & PC + AS4 fiber (Control) & 37.1 & 1.23 \\
HDCB-10-3 & PC + 10 wt\% KM330 + AS4 fiber & 34.7 & $\mathbf{0 . 8 2}$ \\
HDCB-10-6 & PC + 10 wt\% KM653 + AS4 fiber & 31.3 & 0.69 \\
\hline
\end{tabular}

All tests performed at $25^{\circ} \mathrm{C}$ usıng a displacement rate $12.7 \mathrm{~mm} / \mathrm{m} ı$. $G_{1 \mathrm{C}}$ values are the average of four specimens using the area integration method. Prepreg solution was a mixture of 50:50 methylene chloride and chloroform +17 wt $\%$ solıds. 


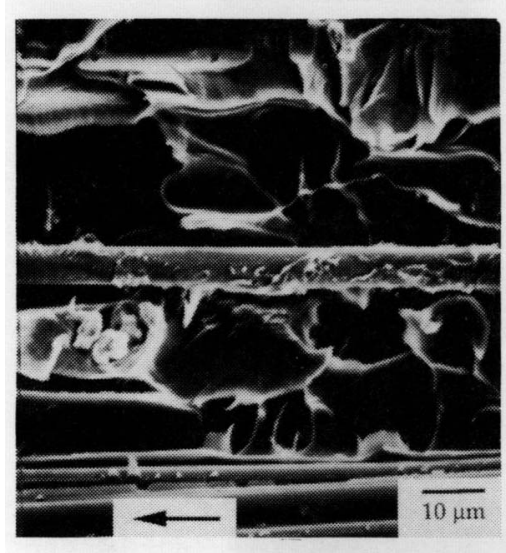

(a)

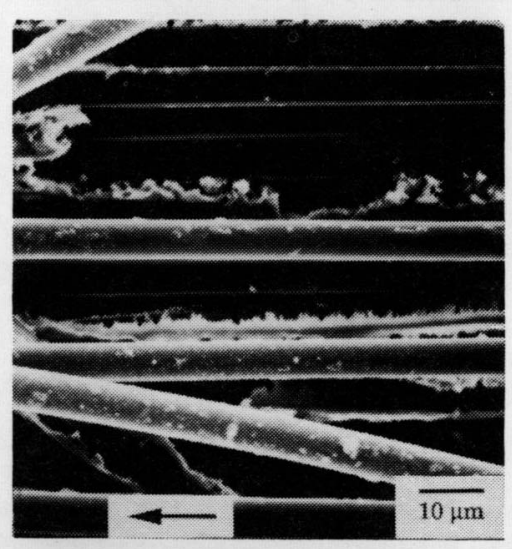

(b)

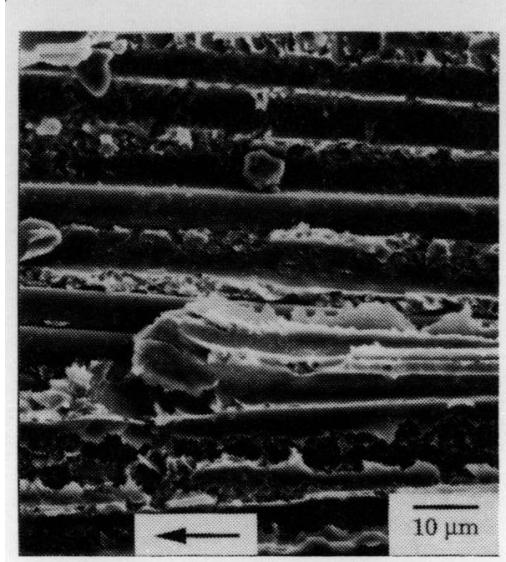

$\ln 1$

Figure 2. SEM photomicrograph of the fracture surface of the HDCB specimens: a) $H D C B$ $P C$, b) $H D C B-10-3$ and c) HDCB-10-6. Arrow indicates crack propagation direction. 


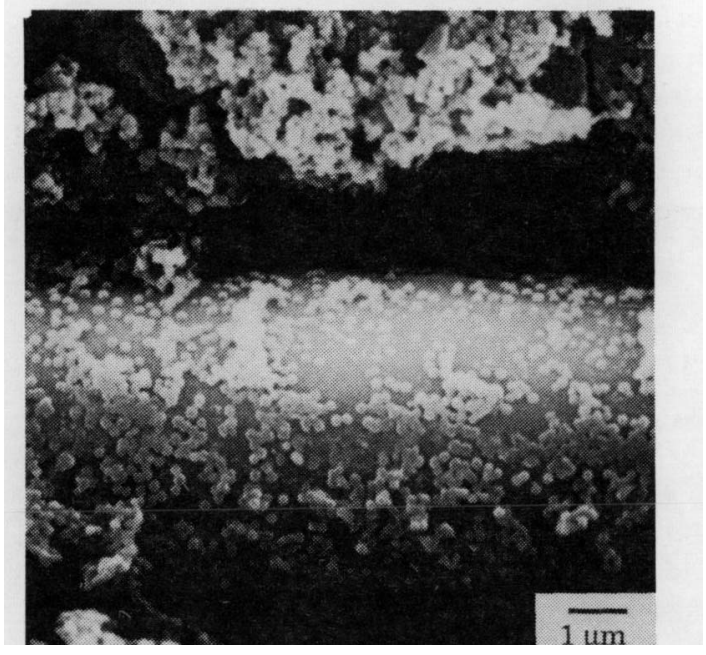

Figure 3. Sodium hydroxide etch of the fracture surface of $H D C B$ specimen HDCB-10-6 reveals that the rubber particles have agglomerated and lie along the fiber surface (Prepreg solution was a mixture of 50:50 methylene chloride and chloroform $+17 w t \%$ solids).

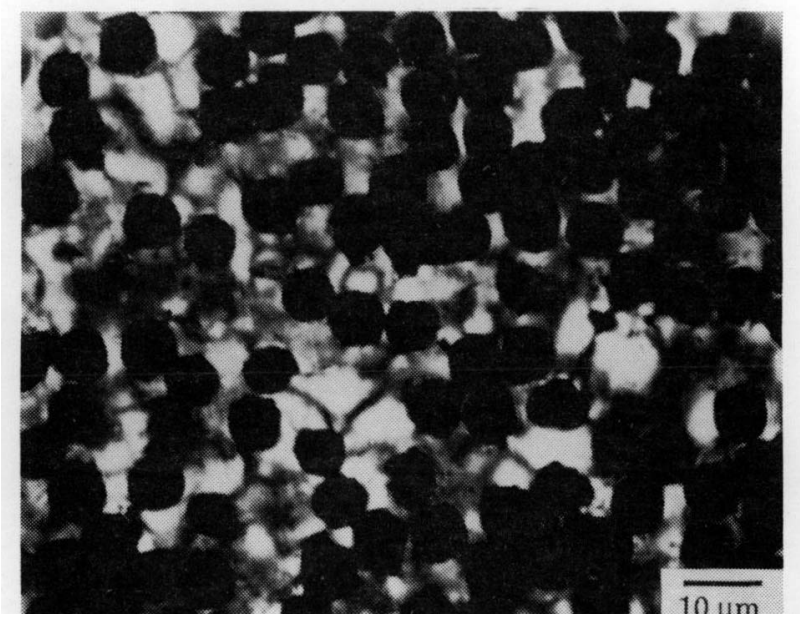

Figure 4. A petrographic thin section of $H D C B$ specimen $H D C B-10-3$. Using optical microscopy and polarized light indicates that the matrix contains regions of crystalline polycarbonate. 
fiber/matrix interface may be beneficial for stress transfer and increase the modulus and strength of the composite. The presence of a crystalline layer along the fiber/matrix interface may be beneficial when the crystalline layer is thin and is limited to the immediate fiber/matrix interface. In the present case where the fiber volume fraction is approaching $65 \mathrm{wt} \%$, the spacing between the fibers is very small. Heterogeneous nucleation of spherulites along the fiber surface could consume the entire region between the fibers. Also, the nucleation of spherulites by any residual crystalline material could produce crystalline regions throughout the entire matrix of the composite. In terms of the interlaminar fracture toughness of these PC composites, the spherulitic morphology is detrimental since crystalline $\mathrm{PC}$ has very low strength.

\section{Effect of Solvent and Composition}

Other potential prepregging solvents were investigated to determine if they would eliminate the formation of a crystalline matrix as well as maintain a stable dispersion of the rubber particles during impregnation. All of the solvents produced a crystalline matrix. One solvent mixture (a 75:25 mixture of methylene chloride and chlorobenzene containing $17 \mathrm{wt} \%$ solids) produced a stable solution (no separation). This prepreg solution was used throughout all future prepreg productions. To further reduce the potential for rubber particle agglomeration, the impact modifier content was reduced from 10 to $5 \mathrm{wt} \%$.

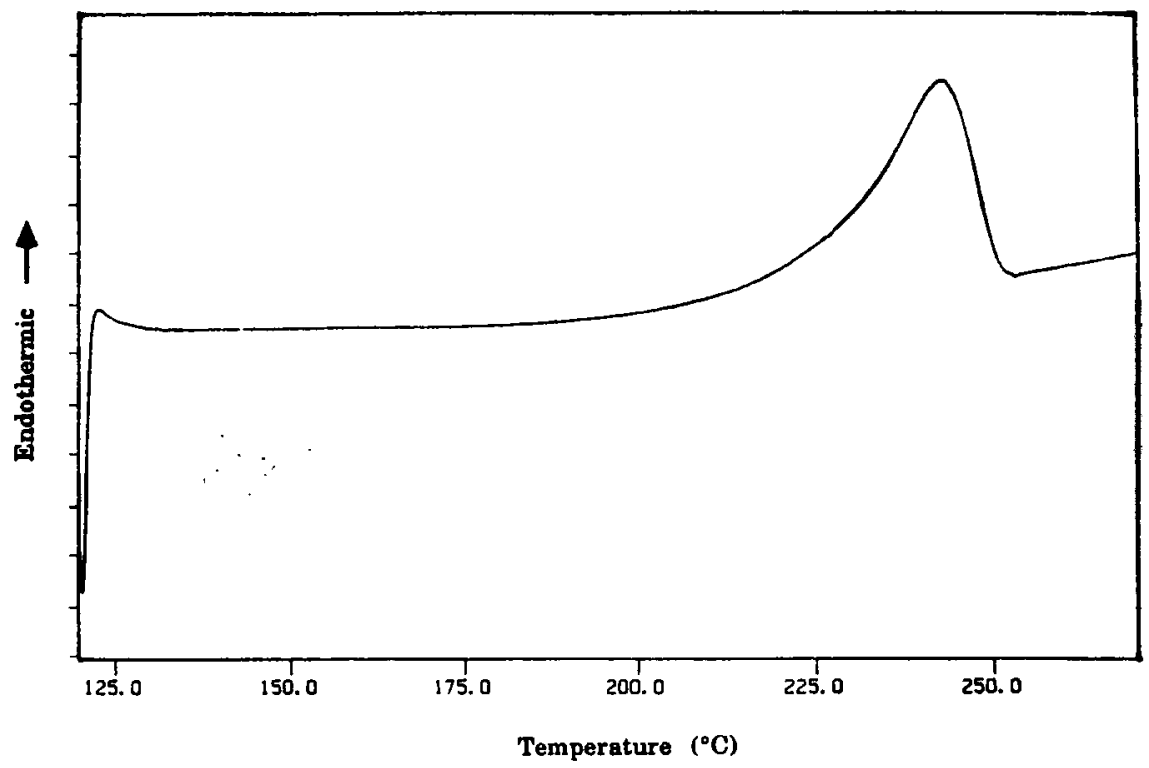

Figure 5. A DSC scan of a sample taken from the impregnated fibers indicates that the removal of the solvent used for prepregging (50:50 methylene chloride and chloroform) produces a crystalline polycarbonate matrix. 
In order to investigate whether or not the rubber particle agglomeration could be reduced by changing the solvent and decreasing the wt $\%$ impact modifier, a second series of composites was made utilizing the same molding practice as before. These test results are shown in Table 3. Comparing the composites produced using $5 \mathrm{wt} \% \mathrm{IM}$ to those using $10 \mathrm{wt} \%$, a slight improvement in the $G_{\text {Ic }}$ values is noted. The modified matrices continue, however, to show no real improvement over the neat PC matrix composite.

SEM photomicrographs of the fracture surfaces, shown in Figure 6, indicate that the adhesion at the fiber/matrix interface has not been significantly improved. A NaOH etch of the fracture surface, shown in Figure 7, reveals that the rubber particle agglomeration has indeed been reduced as a result of lowering the rubber concentration and utilizing the new prepregging solvent. However, the matrix still contains crystalline regions because the processing conditions were not changed.

\section{Effect of Eliminating Crystallinity}

The two impact modified composites were thermally treated to remove the crystalline matrix material by heating the samples above $265^{\circ} \mathrm{C}$ for 20 minutes and cooling to room temperature. Test results of the thermally treated DCB samples are shown in Table 3 . These test results must be viewed with caution. There is a great deal of scatter in the $G_{I c}$ values due to the presence of large voids which formed within the composite during the post thermal treatment. Figure 8 is an optical micrograph of a section taken perpendicular to the fiber direction. It is clear that the voids produced are very large and are preferentially along the interlaminar regions. This microstructure, which we feel was created by the removal of moisture during the thermal treatment, contributed to the large scatter in these test results.

Although the test results cannot be compared directly to the earlier tests the samples can be evaluated in terms of whether or not the thermal treatment may

Table 3. HDCB test results $-5 \mathrm{wt} \%$ impact modified matrix.

\begin{tabular}{llcc}
\hline Sample I.D. & Matrix Resin & $\begin{array}{c}\text { Wt\% } \\
\text { Resin }\end{array}$ & $\begin{array}{c}\mathbf{G}_{\mathbf{l c}} \\
\left(\mathbf{k J} / \mathbf{m}^{2}\right)\end{array}$ \\
\hline HDCB-PC & PC + AS4 fiber (Control) & 37.1 & 1.23 \\
HDCB-5-3 & PC + 5 wt\% KM330 + AS4 fiber & 33.1 & 1.11 \\
HDCB-5-6 & PC + 5 wt\% KM653 + AS4 fiber & 36.6 & $\mathbf{0 . 8 7}$ \\
& Thermally Treated & & \\
HDCB-5-3-TT & PC + 5 wt\% KM330 + AS4 fiber & 33.1 & 0.87 \\
HDCB-5-6-TT & PC + 5 wt\% KM653 + AS4 fiber & 36.6 & 1.20 \\
\hline
\end{tabular}

All tests performed at $25^{\circ} \mathrm{C}$ using a displacement rate $12.7 \mathrm{~mm} / \mathrm{min}$. $G_{1 c}$ values are the average of four specimens using the area integration method. Prepreg solution was methylene chloride $+17 \mathrm{wt} \%$ solids. Thermal treatment consisted of $265^{\circ} \mathrm{C}$ for $20 \mathrm{~min}$. followed by quenching to room temperature. 


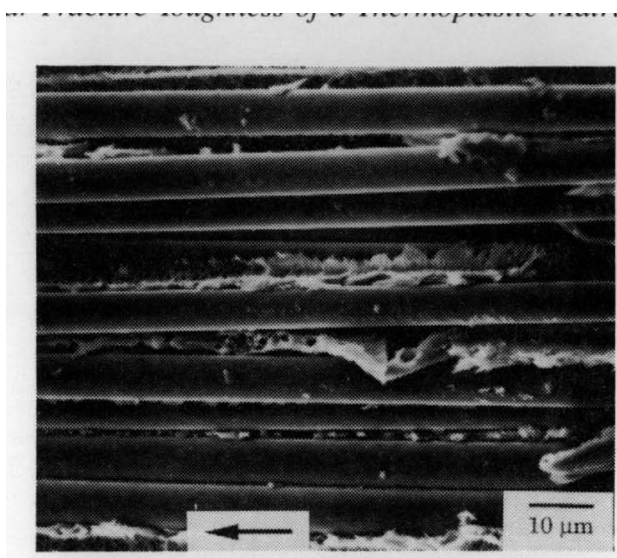

(a)

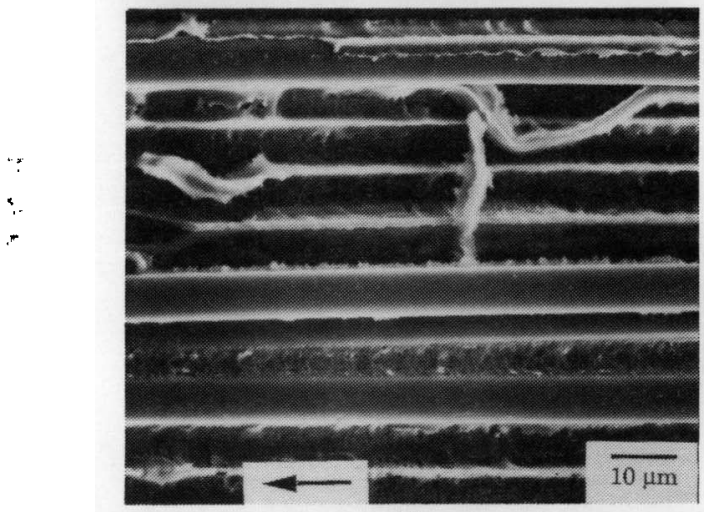

Figure 6. SEM photomicrograph of the fracture surface of the HDCB specimens: a) HDCB-5-3 and b) HDCB-5-6. Adhesion at the fiber/matrix interface has not been improved by reducing the rubber concentration. Arrow indicates crack propagation direction.

have improved the fiber/matrix interface and if the crystalline material was removed. SEM photomicrographs of the thermally treated specimens, shown in Figure 9, do not indicate a substantial improvement in the fiber/matrix adhesion.

Thin sections of the post thermally treated DCB specimens were produced and provided very interesting results. The sections were taken perpendicular to the fiber direction at a position where crack arrest had occurred during testing. Figure 10 is a thin section of HDCB-5-6-TT which shows that the spherulitic morphology of the matrix was eliminated by the thermal treatment. We also found that a plastic zone had developed during loading which extends several fiber diameters below the fracture surface. Apparently when the crystalline material is removed and replaced by a more ductile amorphous matrix, a plastic zone is able to form. This work provides direct evidence supporting models that 


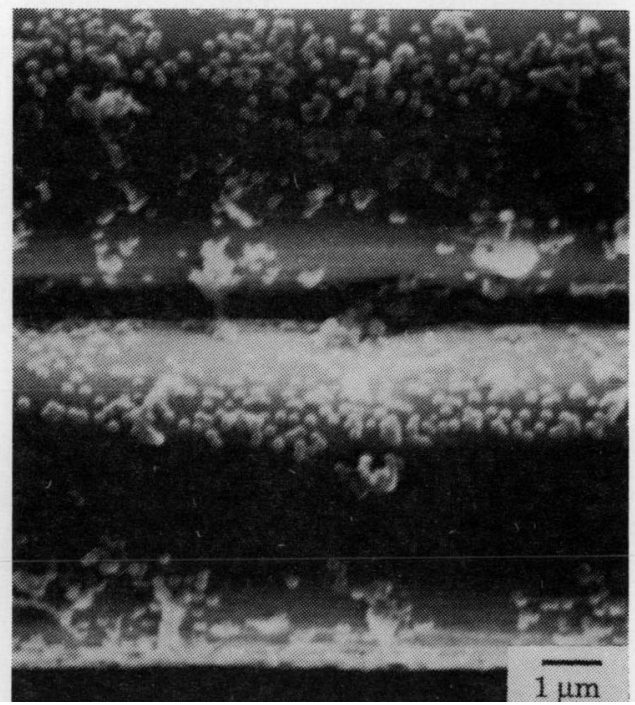

Figure 7. Sodium hydroxide etch of the fracture surface $H D C B$ specimen $H D C B-5-6$ reveals that the agglomeration of rubber particles has been reduced by changing the prepreg solvent and reducing the wt\% rubber to $5 \mathrm{wt} \%$ (prepreg solution was a mixture of methylene chloride $+17 w t \%$ solids).

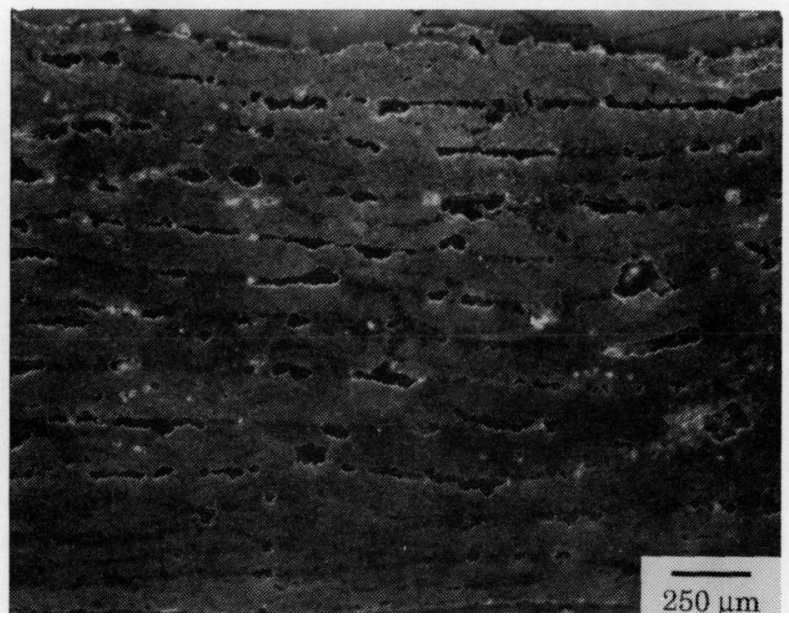

Figure 8. Optical micrograph of the cross-section (perpendicular to the fiber direction) of a post thermally treated HDCB specimen (HDCB-5-6). Large voids developed in the matrix during the thermal treatment to remove the matrix crystallinity (Post thermal treatment was $260^{\circ} \mathrm{C}$ or 20 minutes). 


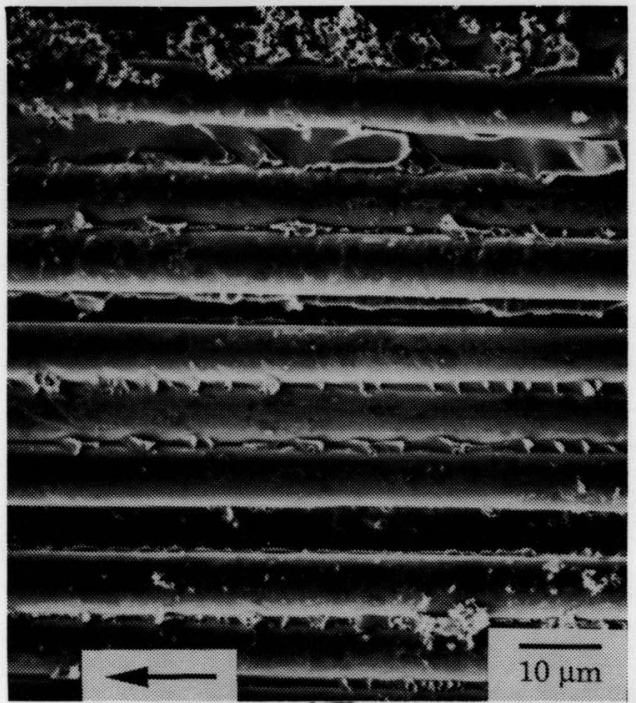

(a)

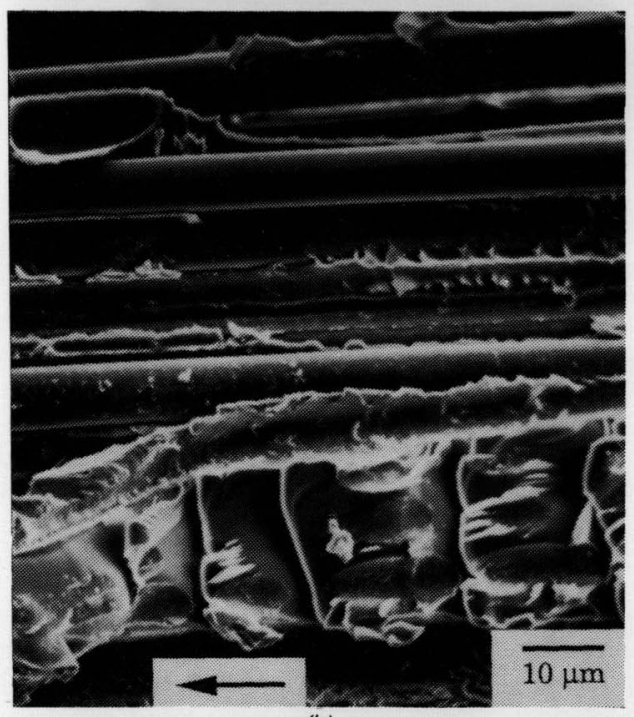

Figure 9. SEM photomicrograph of the fracture surface of the thermally treated HDCB specimens: a) HDCB-5-3-TT and b) HDCB-5-6-TT. The post thermal treatment does not improve the fiber/matrix adhesion. Arrow indicates crack propagation direction. 


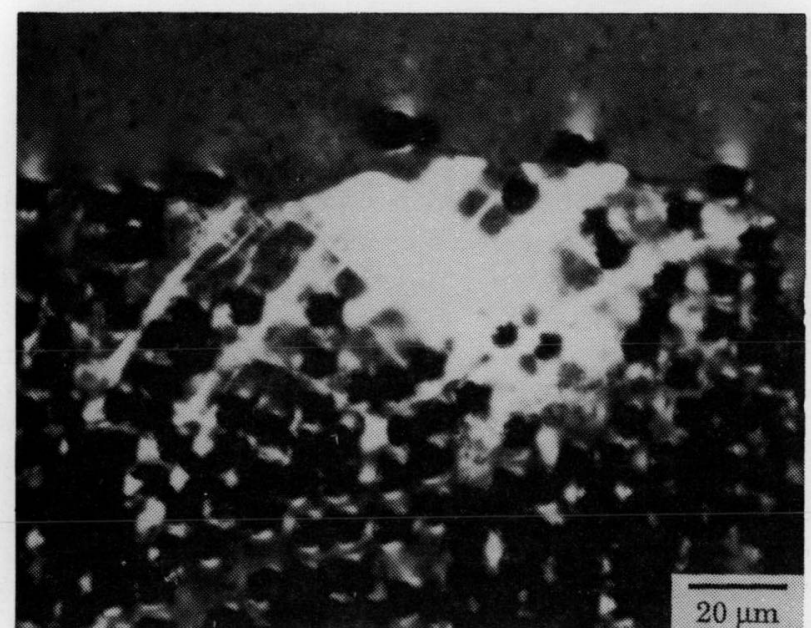

Figure 10. An optical micrograph of a petrographic thin section of a fractured HDCB specimen (HDCB-5-6-TT) which was thermally treated before testing. When viewed using cross polarized light, a plastic zone (birefringent area) is observed to extend several fiber diameters below the fracture surface.

the plastic zone of a high performance composite utilizing a ductile matrix is not limited to a single interfibrillar spacing [23]. The reason these materials do not bring about an increase in the overall interlaminar fracture energy is undoubtedly the premature failure at the fiber/matrix interface. When the interface fails during loading the surrounding matrix is unloaded thus preventing the system from extracting the full potential of the toughened matrix. These results show that the interfacial properties must be improved in order to produce a toughened composite.

\section{Effect of Sizing}

Epoxy sized graphite fibers (AS4-W 12K tows) were used to produce a final set of composites in an attempt to improve the interfacial adhesion. These materials were produced using the proper prepreg solution and a molding practice identical to the thermally treated samples. The DCB results are shown in Table 4. Although the results indicate that the $G_{I_{c}}$ values have been more than doubled by using the epoxy sized fibers, we later determined that these composites contained resin rich interlaminar regions. The primary reason for the significant increase in the interlaminar fracture toughness may well be due to the large increase in the resin content.

The fracture surface was inspected using the SEM to determine if the adhesion was improved by using epoxy sized fibers, and is shown in Figure 11. Qualitatively, it appears that PC does show better adhesion to the epoxy sized fibers than to the unsized fibers. Future composite laminates will be produced using 
epoxy sized fibers to further investigate the influence of the fiber/matrix adhesion on a composite's interlaminar fracture toughness.

\section{CONCLUSION}

Processing conditions have a significant influence on the performance of thermoplastic matrix composites. The solvents used for fiber impregnation and the molding practices will influence the matrix morphology and the fiber/matrix adhesion, which will in turn, control the interlaminar fracture toughness.

Solvents used for impregnating fibers with a two phase matrix material must be evaluated to assure that separation does not occur. If a separation should occur, the matrix will not be homogeneous and a poor fiber/matrix interface may be created. The solvents may also induce crystallinity within the prepregs which can be carried over into the final composite if an appropriate molding procedure is not used to eliminate it.

In this particular case, we have demonstrated using a rubber modified PC matrix composite that once the rubber agglomerations and the matrix crystallinity are eliminated, a plastic zone is capable of forming during loading. Most importantly, the plastic zone is not restricted to a single interfibrillar region. Apparently the constraint of the matrix due to the presence of the fibers is not as great as one would expect. Therefore, methods for improving a composite's interlaminar fracture toughness are not restricted to the interlaminar region. Toughening techniques which are capable of operating within the high density fiber regions could also produce tough composites.

A critical factor in developing tough thermoplastic composites is the fiber/matrix interfacial adhesion. Our attempt of using an epoxy sized fiber does show an improvement in adhesion of the PC matrix to the fibers. However, this is not expected to be the optimum condition. Although a great deal of work in developing sizing agents to improve adhesion between thermosetting resins and graphite fibers has been done, this is not true for thermoplastic resins. Until similar methods or sizing agents are developed for thermoplastic resins, the potential use of a toughened thermoplastic resin as a matrix material for a high performance fiber composite cannot be properly evaluated.

Table 4. HDCB test results -5 wt\% impact modified matrix utilizing epoxy sized graphite fibers.

\begin{tabular}{|c|c|c|c|}
\hline Sample I.D. & Matrix Resin & $\begin{array}{l}\text { Wt } \% \\
\text { Resin }\end{array}$ & $\begin{array}{c}G_{I c} \\
\left(\mathbf{k J} / \mathbf{m}^{2}\right)\end{array}$ \\
\hline HDCB-PC-ES & $P C+A S 4-W$ fiber (Control) & 35.4 & 2.6 \\
\hline HDCB-5-3-ES & $\begin{array}{l}\mathrm{PC}+5 \mathrm{wt} \% \mathrm{KM} 330+\mathrm{AS} 4-\mathrm{W} \\
\text { fiber }\end{array}$ & 36.22 & 0.82 \\
\hline
\end{tabular}

All tests performed at $25^{\circ} \mathrm{C}$ using a displacement rate $12: 7 \mathrm{~mm} / \mathrm{min}$. $G_{l c}$ values are the average of four specimens usıng the area integration method. Prepreg solution was methylene chioride +17 wt\% solids. 


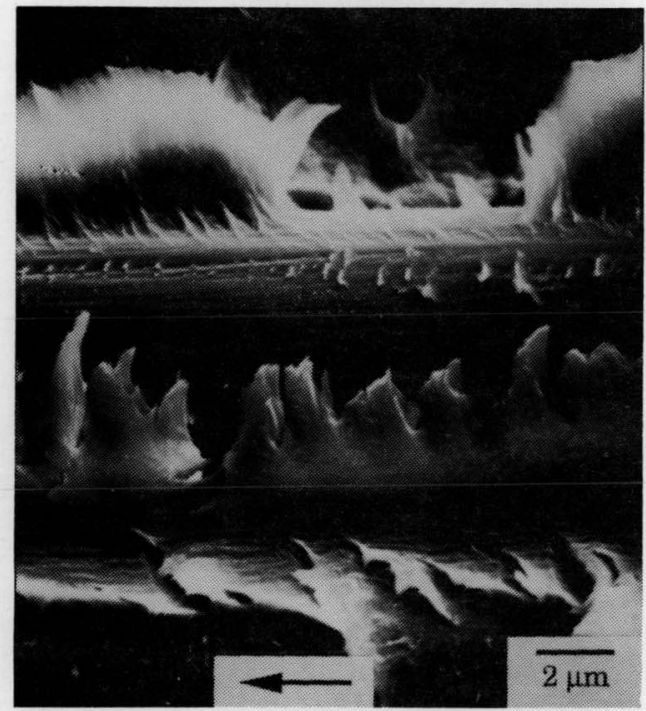

(a)

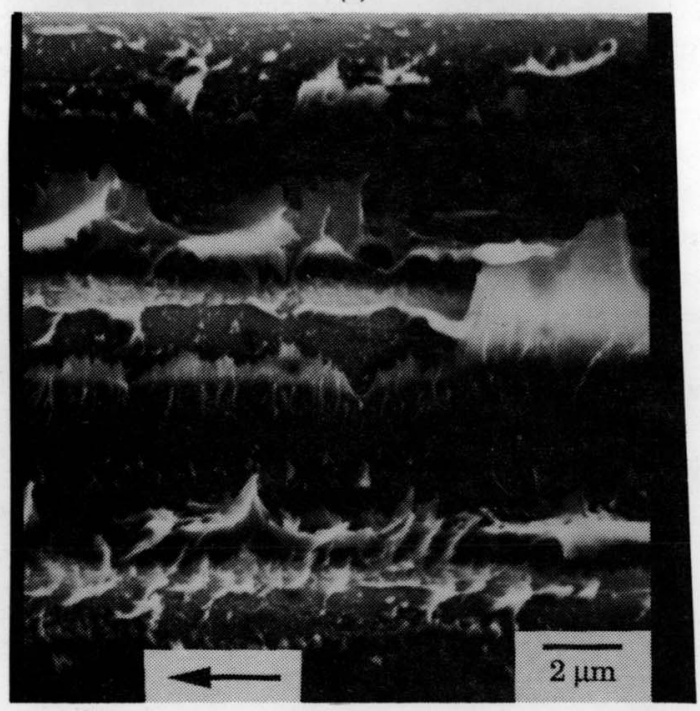

Figure 11. SEM photomicrograph of the fracture surface of HDCB specimens: a) HDCB$P C-E S$ and b) HDCB-5-3-ES. The matrix has undergone plastic flow during fracture and the matrix appears to have good adhesion to the epoxy sized fibers. Arrow indicates crack propagation direction. 


\section{ACKNOWLEDGEMENT}

We would like to thank Dr. K. Riew (BFGoodrich) and Dr. E. A. Flexman (E. I. du Pont de Nemours) for producing our modified matrix materials. We also wish to thank NASA-Langley and Dr. N. Johnston for producing our composite samples. The work is partially supported by a NASA grant, No. NAG-1-607.

\section{REFERENCES}

1. Morley, J. G. High Performance Fibre Composites, London:Academic Press (1987).

2. Manders, P. W. and W. C. Harris. "A Parametric Study of Composite Performance in Compression-After-Impact Testing." SAMPE Journal. pp. 47-51 (November/December 1986).

3. Lang, R. W., M. Heym, H. Tesch and H. Stutz. "Influence of Constituent Properties on Interlaminar Crack Growth in Composites," High Tech-The Way Into the Eighties, European SAMPE, K. Brunsch. H.-D. Golden and L.-M. Herkert, eds. Elsevier Science, Amsterdam, pp. $261-272$ (1986).

4. Lagace, P. A. "Delamination in Composites: Is Toughness the Key?" SAMPE Journal, pp. 53-60 (November/December 1986).

5. Crick, R. A.. D. C. Leach and D. R. Moore. "Interpretation of Toughness in Aromatic Polymer Composites Using a Fracture Mechanics Approach," SAMPE Journal, pp. 30-36 (November/ December 1986)

6. Lee. S. M. and G. D. M. Disalvo. "Resin Properties/Laminate Fracture Toughness Correlation," 30th National SAMPE Symposium, pp. $1346-1355$ (1985).

7. Devitt, D. F., R. A. Schapery and W. L. Bradley. "A Method for Determining the Mode I Delamination Fracture Toughness of Elastic and Viscoelastic Composite Materials," Journal of Composite Materials, 14:270-285 (1980).

8. Hibbs, M. F.. M. K. Tse and W. L. Bradley. "Interlaminar Fracture Toughness and Real-Time Fracture Mechanism of Some Toughened Graphite/Epoxy Composites," Toughened Composites, ASTM STP 937. N. J. Johnston, ed., American Society for Testing and Materials, Philadelphia, pp. $115-130$ (1987).

9. Hunston, D. L. "Composite Interlaminar Fracture: Effect of Matrix Fracture Energy," Composites Technology Review, 6(4):176-180 (1984)

10. Hunston, D. L., R. J. Moulton, N. J. Johnston and W. D. Bascom. "Matrix Resin Effects in Composite Delamination: Mode I Fracture Aspects," Toughened Composites, ASTM STP 937, N. J. Johnston, ed., American Society for Testing and Materials, Philadelphia, pp. 74-94 (1987).

11. Schultz, J. . L. Lavielle and C. Martin. "The Role of the Interface in Carbon Fibre-Epoxy Composites," Journal of Adhesion. 23:45-60 (1987).

12. Yee, A. F. "Modifying Matrix Materials for Trugh Composites," Toughened Composites, ASTM STP 937. N. J. Johnston, ed.. American Society for Testing and Materials, Philadelphia, pp. 377-396 (1987).

13. Jordan, W. M. and W. L. Bradley. "Micromechanisms of Fracture in Toughened Graphite-Epoxy Laminates." Toughened Composites, ASTM STP 937, N. J. Johnston, ed., American Society for Testing and Materials. Philadelphia, pp. 95-114 (1987).

14. Lee, S. M. "Correlation Between Resin Material Variables and Transverse Cracking in Composites," Journal of Materials Science, 19:2278-2288 (1984).

15. Yee, A. F. and R. A. Pearson. "Toughening Mechanisms in Elastomer-Modified Epoxies Part I Mechanical Studies," Journal of Materials Science, 21:2462-2474 (1986).

16. Pearson, R. A. and A. F. Yee. "Toughening Mechanisms in Elastomer-Modified Epoxies Part II Microscopy Studies," Journal of Materials Science, 21:2475-2488 (1986).

17. Bascom, W. D. R. Y. Ting, R. J. Moulton, C. K. Riew and A. R. Seibert. "The Fracture of an Epoxy Polymer Containing Elastomeric Modifiers," Journal of Materials Science, 16:2657-2664 (1981). 
18. Parker, D. S. and A. F. Yee. "Toughening of a Thermoplastic Matrix Composite: Processing Issues," Proceedings of The American Socien for Composites Third Technical Conf.. Seattle. Washington. pp. 270-279 (1988).

19. Parker, D. S. and A. F. Yee. To be published.

20. "Standard Test for Toughened Resin Composites," NASA Reference Publication 1092, National Aeronautics and Space Administration, Langley Research Center, Hampton, Virginia (1983).

21. Parker, D. S. and A. F. Yee. "A Petrographic Thin Sectioning Technique for Evaluating Composite Materials," accepted for publication in the Journal of Materials Science Letters.

22. Kardos. J. L., F. S. Cheng and T. L. Tolbert. "Tailoring the Interface in Graphite-Reinforced Polycarbonate," Polvmer Engincering and Scienc', 13(6):455-461 (1973).

23. Bradley, W. L. and R. N. Cohen. In Delamination and Debonding of Materials. ASTM STP 876. p. 389 (1985)

\section{BIOGRAPHIES}

\section{S. Parker}

Doug Parker received his B.S. in Metallurgical Engineering from Michigan Technological University in 1980. After graduation he worked as a Metallurgical Engineer for the Aluminum Company of America (ALCOA). In 1985 he began his graduate studies at the University of Michigan and in 1987 received his M.S. in Materials Science and Engineering. Currently he is completing the requirements for his Ph.D.. investigating methods for toughening bulk polymers and polymer composites utilizing thermosetting and thermoplastic matrices.

\section{A. F. Yee}

A. F. Yee obtained his B.S. and Ph.D. degrees in chemistry from the University of California. From 1971 to June 1985 he was on the staff of the Polymer Physics Unit of the Corporate R\&D Center of the General Electric Company in Schenectady. In 1985 he became a professor in the Materials Science and Engineering Department at the University of Michigan in Ann Arbor, Michigan. His current research interests include relaxation phenomena, nonlinear viscoelasticity and failure and toughening mechanisms in plastics and composites. 